\title{
Gamma radiation effect on sisal / polyurethane composites without coupling agents
}

\author{
Marina Cardoso Vasco ${ }^{1 *}$, Salvador Claro Neto ${ }^{2}$, Eduardo Mauro Nascimento ${ }^{3}$ and Elaine Azevedo ${ }^{3}$ \\ ${ }^{1}$ Department of Mechanical Engineering and Aerospace, University of Patras, Patras, Greece \\ ${ }^{2}$ Instituto Qumica de São Carlos, Universidade de São Paulo - USP, São Carlos, SP, Brazil \\ ${ }^{3}$ Programa de Pós-graduação em Engenharia Mecânica e de Materiais, Universidade Tecnologica Federal \\ do Paraná - UTFPR, Curitiba, PR, Brazil \\ *marina.mcv@gmail.com
}

\begin{abstract}
Natural fibers and polyurethane based composites may present chemical bonding between the components of the polymer and the lignin of the fiber. The incidence of radiation can cause degradation of the polymeric material and alter its mechanical properties. The objective of this study was to obtain and characterize cold pressed composites from polyurethane derived from castor oil and sisal fibers, without coupling agents, through thermogravimetric and mechanical tests, before and after the incidence of $25 \mathrm{kGy}$ dose of gamma radiation. Woven composites that were not irradiated had maximum values of $4.40 \mathrm{GPa}$ for flexural elastic modulus on three point flexural test and dispersed fiber composite that were not irradiated had maximum values of $2.25 \mathrm{GPa}$. These materials are adequate for use in non-structural applications in radiotherapy and radiodiagnostic rooms.
\end{abstract}

Keywords: gamma radiation, sisal, polyurethane, mechanical properties, green composite.

\section{Introduction}

The use of natural fibers as load or reinforcement in polymeric composites is increasing in the last years. Characteristics such as processing flexibility, high specific stiffness and low cost make them attractive to industrial applications ${ }^{[1-5]}$. Polymeric matrices are preferred because of their low cost and ease of processing, and their main functions are joining the fibers, distributing stresses and stopping crack propagation in the material ${ }^{[6]}$. Conventional polymers used in radiotherapy furniture and radio diagnostic rooms, such as adhesives and agglomerates, have their mechanical properties considerably altered when exposed to high energy radiation ${ }^{[7]}$.

The effects of gamma radiation in polyurethane derived from castor oil adhesive specimens were studied by Azevedo et al. ${ }^{[8]}$, and they concluded that there were no significant alterations of the mechanical properties when materials were irradiated with doses up to $100 \mathrm{kGy}$, since the main effect of radiation in this polymer is the formation of cross-linked bonds within polymeric chains.

The lack of adhesion between the fiber and the matrix is one of the greatest concerns regarding the production of bio composites. Mechanical loads are held by the fibers, and the matrix/fiber interface should transfer the applied load from the matrix to the fibers in order to achieve the desired mechanical strength ${ }^{[3,9]}$. In general, natural fibers are hydrophilic and do not show good adhesion with hydrophobic polymers normally used as composite matrices ${ }^{[9]}$.

Many different approaches described elsewhere ${ }^{[9-16]}$ have been explored in order to improve the fiber/matrix adhesion. They include the chemical modification of the fiber before the composites processing, either through esterification ${ }^{[17-22]}$, eterification ${ }^{[17,21,22]}$, silane ${ }^{[11,12,21]}$ or isocyanate ${ }^{[9,23]}$ treatments,

or through physical means as plasma ${ }^{[1,13,24,25]}$ or corona ${ }^{[24,25]}$ treatments, as well as the modification of the polymeric matrix $^{[26,27]}$.

During the process of polymerization of the polyurethane/sisal composite utilized in this work, the active hydrogen present in the sisal lignin, either in its hydroxyl or carboxyl groups, may chemically interact with free isocyanate from polyurethane and form urethane bonds or carbamic anhydride ${ }^{[28]}$. Chemical interaction between isocyanate and lignin may reinforce the polymer-fiber interface, leading to a better load distribution throughout the composite structure when it's subjected to mechanical stresses. This may enhance its mechanical performance with no need of adding coupling agents or conducting pre-treatments on the fibers.

The aging resistance of sisal fibers is good ${ }^{[7]}$, and they are able to decrease the effect of gamma radiation on the mechanical properties of the polyurethane matrix, as well as to increase the fiber/matrix cohesion. Huang et al. ${ }^{[29]}$ observed the influence of gamma, UVA, and UVC radiations on the flexural strength of composites with different volumetric proportions of fiber and resin, and concluded that the incidence of radiation degraded the mechanical properties of the studied materials, without affecting the necessary characteristics for their use as accessories in radiotherapy and radio diagnostic rooms. However, the possible changes in chemical affinity between the components and the mass loss with temperature as a function of the incident radiation were not studied.

The aim of this work is to evaluate the mechanical properties of composites made with castor oil derived polyurethane and dispersed and woven sisal fibers, with no compatibility treatments, before and after incidence of 
a $25 \mathrm{kGy}$ dose of gamma radiation. This dose is the same used sterilization of medical materials. Specimens were characterized and evaluated by means of thermogravimetric analysis (TGA), cryogenic fracture tests, nanoindentation and nanoscratch tests, Izod impact test and flexural test, and fracture surfaces were analyzed by scanning electron microscopy (SEM).

\section{Materials and Methods}

The polyurethane used in this work was donated by the company Cequil, from Araraquara - SP, Brazil. It was supplied as a bi-component, a poliol and a pre-polymer, identified as 442 and 253, respectively. The preparation of the polymer was made according to the supplier instructions, and the ratio poliol:pre-polymer was 1:1 for all specimens. The setting time of the polymer was $24 \mathrm{~h}$.

Sisal fibers were acquired from local stores in Curitiba-PR, Brazil, and there was no concern regarding its precedence. Two different geometries were used: (1) dispersed fibers of approximately $5 \mathrm{~mm}$ in length, and (2) bidirectional woven with thickness of about $2 \mathrm{~mm}$ composed of sisal threads with approximate diameter of $1 \mathrm{~mm}$. Fibers was previously kept in an oven at $70{ }^{\circ} \mathrm{C}$ for six hours in order to eliminate moisture, and this was the only processing that they subjected to before mixing with the polymer. Two different sources of fibers were used, since it was not possible to make dispersed fibers form the woven, because it resulted in agglomerates, making the homogenization of the composite very difficult.

Fibers and polymer were manually mixed with a fiber:polymer ratio of $80 / 20 \mathrm{wt} \%$, and rectangular sheets $3-4 \mathrm{~mm}$ thick were produced. The mixture was pressed at room temperature in a hydraulic press, and the applied pressure was 266.6 $\mathrm{Pa}$. No vacuum was made during pressing. Specimens were then cut from pressed sheets for characterizations, and the dimensions of the specimens used for destructive tests are in accordance with ASTM 790-03 and ASTM D 256 standards (flexure tests and impact tests, respectively).

Gamma irradiation tests, with dose of $25 \mathrm{kGy}$, were performed by the company Embrarad - Cotia/SP with the aid of industrial source Cobalt 60 MDS Nordion JS-9600.

The thermogravimetric analyses (TGA) were carried out in a Perkin Elmer STA 6000 thermo scale, and the following parameters were used:

- Specimen mass: 4.0 to $5.0 \mathrm{mg}$;

- Temperature range: $50{ }^{\circ} \mathrm{C}$ to $800^{\circ} \mathrm{C}$;

- Heating rate: $10{ }^{\circ} \mathrm{C} / \mathrm{min}$;

- Flow of $\mathrm{N}_{2}$ atmosphere: $20 \mathrm{~mL} / \mathrm{min}$.

Flexural tests were performed according to the ASTM D790-03 standard in an EMIC DL10000 universal tester, with load cell of $5 \mathrm{kN}$ and test speed of $1 \mathrm{~mm} / \mathrm{min}$. To determine impact resistance, test specimens of $55 \times 10 \times 4 \mathrm{~mm}$ (length $\times$ width $\times$ thickness) were submitted to Izod impact test in Ceast equipment, model Resil 25, notched in Ceast chisel with depth of $2.54 \pm 0.1 \mathrm{~mm}$, according to the ASTM
D256 standard. All woven composites specimens were cut in a parallel direction to the length of the fibers.

Scanning Electron Microscopy was performed in a Zeiss microscope, model EVO MA 15, and it was used to evaluate the surface of fibers after drying and the fracture surface of the composites after flexural test.

\section{Results and Discussion}

Table 1 shows the flexural properties of polyurethane derived from castor oil before and after the gamma irradiation with dose of $25 \mathrm{kGy}$. A slight increase on flexural stress and flexural elastic modulus after irradiation is noticed, which, according to Azevedo et al. ${ }^{[8,30]}$, can be attributed to the formation of crosslink bonds in the polymeric chains caused by the gamma radiation incidence.

Figure 1 shows the obtained TGA curves of the dispersed fibers composite without irradiation. A thermal event starting at $50{ }^{\circ} \mathrm{C}$ can be observed, and this can be attributed to the presence of water ${ }^{[31]}$ and other substances that are present onto the surface of the fibers. This thermal event finishes at $150{ }^{\circ} \mathrm{C}$, and the next one occurs at $520^{\circ} \mathrm{C}$. It can be assumed that the thermal behavior of the composite is combination of the thermal behavior of its individual components, and the phase with higher volumetric fraction gives the major contribution. The $20 \%$ of the mass remaining at the end of the test can be identified as burning residues.

The TGA curves of the dispersed fibers composite after gamma irradiation with dose of $25 \mathrm{kGy}$ are shown in Figure 2. Comparing to the non-irradiated material, it can be noticed that the temperatures of the thermal events did not change, but the peaks intensities decreased in the derivative curve, which is a sign of degradation of the fibers caused by the

Table 1. Stress rupture values in flexion and elastic modulus in bending the polyurethane derived from castor oil before and after incidence of gamma radiation ( $25 \mathrm{kGy}$ dose).

\begin{tabular}{lcc}
\hline \multicolumn{1}{c}{ PU } & $\begin{array}{c}\text { Flexural stress } \\
\text { (MPa) }\end{array}$ & $\begin{array}{c}\text { Elastic modulus } \\
\text { (GPa) }\end{array}$ \\
\hline Before irradiation & $42 \pm 3$ & $1.64 \pm 0.12$ \\
After irradiation & $47 \pm 12$ & $1.66 \pm 0.50$ \\
\hline
\end{tabular}

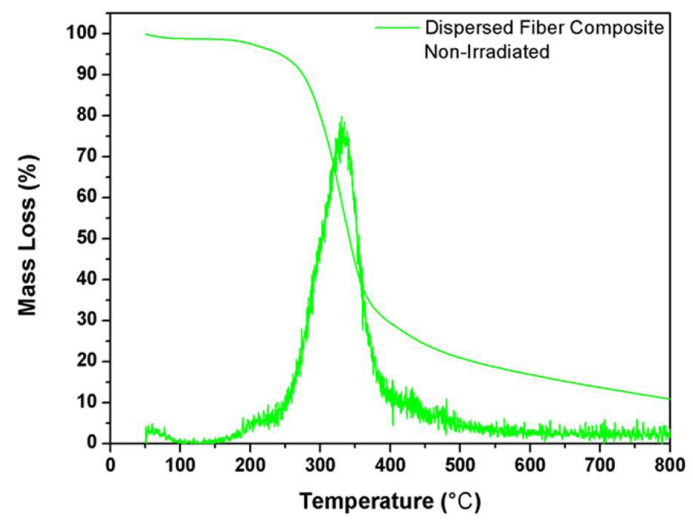

Figure 1. Thermogravimetric Analysis curves obtained for the non-irradiated dispersed sisal fibers composite. 
incident radiation. The amount of burning residues after the test showed no significant variation.

The curves obtained from thermogravimetric analysis of the non-irradiated woven composite are shown in Figure 3. A thermal event starts at $50^{\circ} \mathrm{C}$ and finishes at $150{ }^{\circ} \mathrm{C}$, and this event is also attributed to the presence of water, similar to the previous cases. Following that, another thermal event starts at $150{ }^{\circ} \mathrm{C}$ and finishes at $520^{\circ} \mathrm{C}$, and the same amount $(20 \%)$ of burning residues remains at the end of the test.

Figure 4 shows the TGA curves of the woven composite after gamma irradiation. Again, when comparing to the non-irradiates specimens, no variation of the initial and final temperatures of the thermal events was observed. The decreasing intensity of the peaks in the derivative curve indicates the influnece of the gamma radiation on the degradation of the sisal woven, and the burning residues mass was the same as observed previously.

It was observed that the intensity of the thermal events for the sisal woven composites occurring in the temperature range between $250^{\circ} \mathrm{C}$ and $450{ }^{\circ} \mathrm{C}$ is larger than its correspondents for dispersed fibers composites. That could be explained by the difference in morphology of the reinforcements, implying in different modes of thermal energy transference inside the materials.

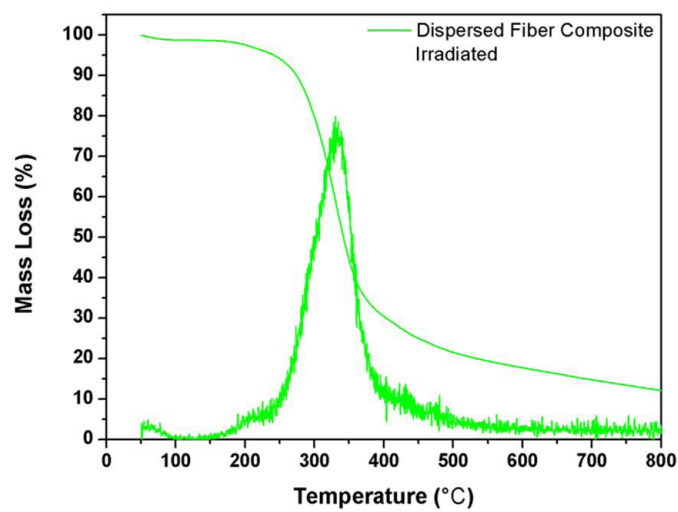

Figure 2. Thermogravimetric Analysis curves obtained for the gamma irradiated dispersed sisal fibers composite.

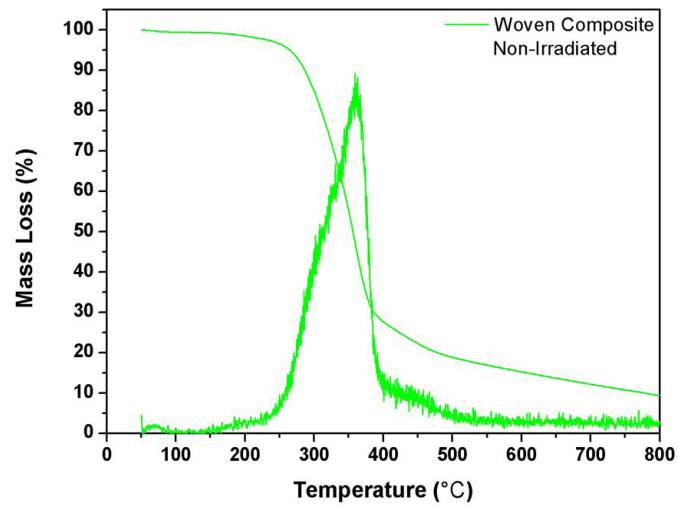

Figure 3. Thermogravimetric Analysis curves obtained for the non-irradiated woven sisal fibers composite.
Figure 5 shows a SEM micrograph of the fracture surface after cryogenic fracture of dispersed fibers composite without incidence of gamma radiation.

From Figure 5 one can see that there are no voids or gaps on the fiber-matrix interface, suggesting that, besides the mechanical interlocking, fibers may present chemical affinity with this type of polyurethane, increasing surface adhesion and providing better mechanical properties, since load transfer becomes more efficient. More than one failure mode was observed in the fracture surfaces of the composites, which is expected for this type of material. Fiber breakage and tearing, as well as polymer matrix fracture were observed. The polymer fracture was of brittle in nature, evidenced by mirrored areas starting at stress concentration points such as bubbles, which are inherent to the manufacturing process of the polymer, impurities at the fibers surface and fibers edges. Figure 6 shows a SEM micrograph of the dispersed fibers composite after gamma irradiation. It is observed that there are no gaps around the fiber-polymer interface, suggesting that even after the incidence of the applied dose of gamma radiation the chemical affinity between the fibers and the polyurethane matrix is maintained. It is also observed that the amount of empty regions in the fibrils interior has enhanced, which can indicate embrittlement due to radiation,

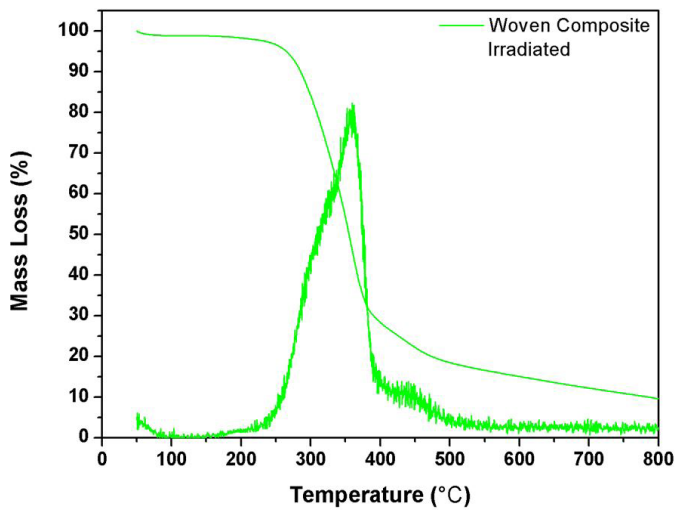

Figure 4. Thermogravimetric Analysis curves obtained for gamma irradiated woven sisal fibers composite.

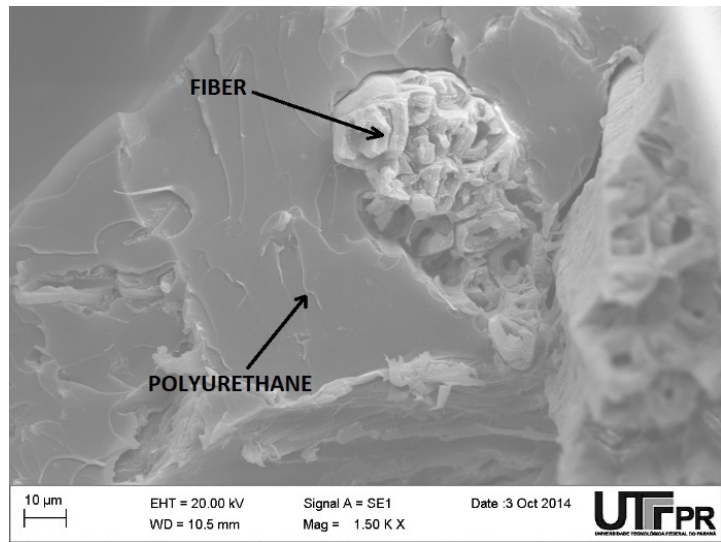

Figure 5. SEM micrograph of cryogenic fracture of non-irradiated dispersed sisal fibers composite. 
behavior also evidenced by detachment of micro fibrils in other regions of the material.

Figures $7 \mathrm{a}$ and $7 \mathrm{~b}$ show the surface fractures after cryogenic fracture of the non-irradiated and irradiated sisal woven composites, respectively. In both cases, the fracture aspect was the same observed for the dispersed fiber composite, with embrittlement of micro fibrils after irradiation and no presence of interfacial gaps between the fibers and the polymer matrix.

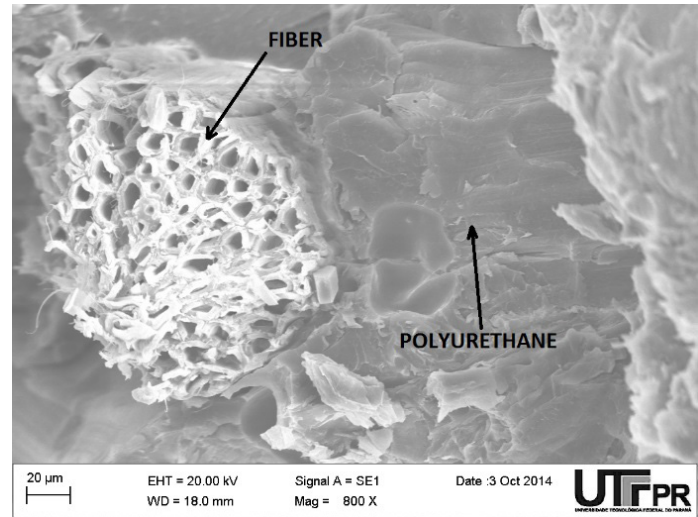

Figure 6. SEM micrograph of cryogenic fracture of gamma irradiated dispersed sisal fibers composite, dose of $25 \mathrm{kGy}$.
The absence of fiber-matrix interfacial gaps was reported by other authors ${ }^{[32,33]}$ only for fibers that were treated with coupling agents, witchy suggests that the chemical affinity between the materials investigated in this work is suitable even without the use of coupling agents.

The results obtained for flexural stress and elastic modules before and after the incidence of gamma radiation are shown in Figures 8a and 8b. Specimens were identified as follows: DF - dispersed fiber composite; $\mathrm{W}$ - woven fiber composite; NI - non-irradiated.

Both flexural stress and elastic modules of dispersed fibers composites were lower when compared to woven composites and non-reinforced polyurethane. Such result could be attributed to the fact that the fibers extremities act as stress risers and crack initiation sites, decreasing the material flexural strength ${ }^{[6]}$. In this case, the higher fiber-to-matrix volume ratio contributed to this decrease in flexural strength, since there are more stress risers points ${ }^{[34,35]}$. It was also observed that the incidence of gamma radiation decreased the mechanical strength of the materials, because of the degradation on fibers caused by radiation ${ }^{[7]}$, which was evidenced by the surface fractures observation. The highest flexural strength was obtained by the non-irradiated sisal woven composite, with an increase of $190 \%$ in flexural strength and $268 \%$ in flexural elastic modules when compared to the non-irradiated and non-reinforced polyurethane.

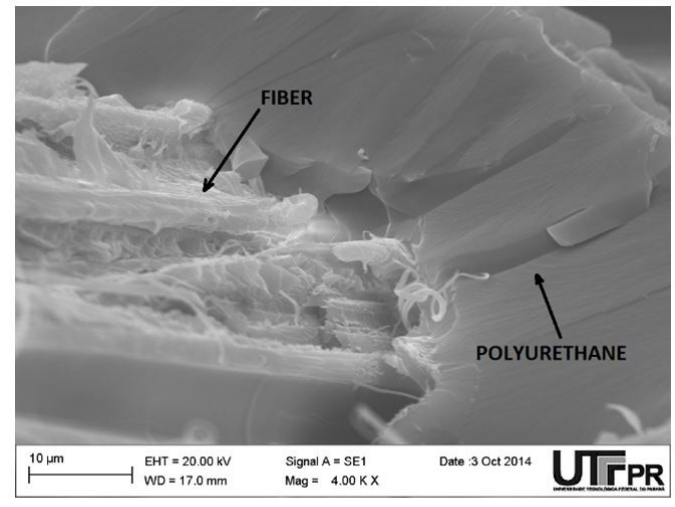

(a)

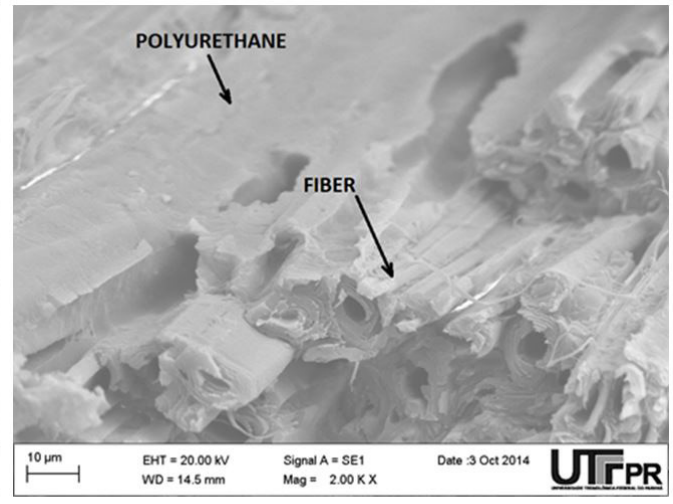

(b)

Figure 7. SEM micrograph of fracture surfaces after cryogenic fracture of woven sisal fibers composite: (a) before gamma radiation, and (b) after gamma irradiation with dose of $25 \mathrm{kGy}$.

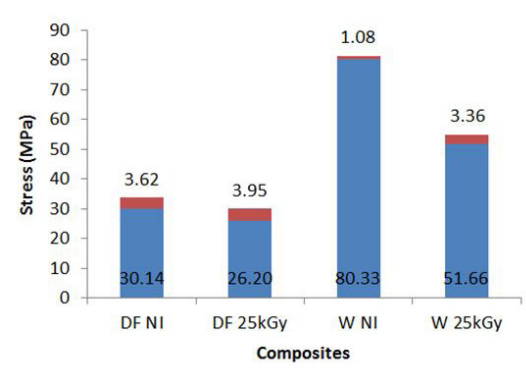

(a)

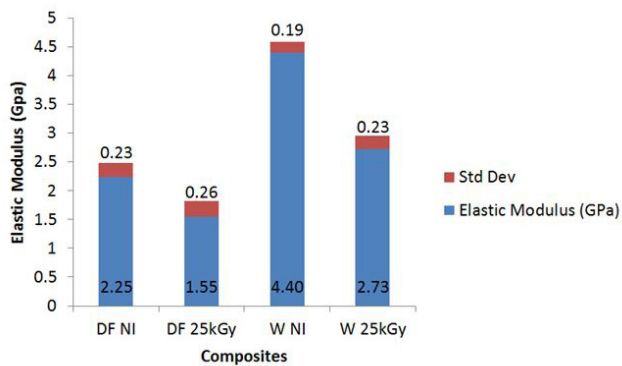

(b)

Figure 8. Average values and standard deviations for (a) flexion stress, and (b) flexion elastic modulus for each composite, before and after gamma radiation incidence with dose of $25 \mathrm{kGy}$. 
Table 2. Impact resistance values of the dispersed fibers and woven composites before and after incidence of gamma radiation (dose of $25 \mathrm{kGy}$ ).

\begin{tabular}{lc}
\hline \multicolumn{1}{c}{ Composite } & Impact resistance $\left(\mathbf{k J} / \mathbf{m}^{2}\right)$ \\
\hline Dispersed fibers without radiation & $10.4 \pm 3.4$ \\
Dispersed fibers 25 kGy & $13.1 \pm 3.2$ \\
Woven without radiation & $8.7 \pm 1.3$ \\
Woven 25 kGy & $9.1 \pm 1.3$ \\
\hline
\end{tabular}

The comparison between impact resistance of the composites before and after irradiation is shown in Table 2 . Higher values were measured for disperse fibers composite, probably because the fibers extremities acts as crack arresters, impeding the crack propagation and consequently increasing impact resistance. It was also noticed that standard deviation values for dispersed fibers composites are higher than for woven composites, due to lack of uniformity of fibers dispersion among different specimens. The manufacturing process of the specimens was made manually, which may have originated heterogeneous regions with different fibers concentration within the polymer matrix.

The impact resistance of both composites increased after the incidence of gamma radiation, as a result of the higher density of cross-linked bonds in the polyurethane matrix.

Silva et al. ${ }^{[1]}$ reported impact resistance values of $23 \mathrm{~kJ} / \mathrm{m}^{2}$ for short untreated sisal fibers with fiber content of $20 \%$ in volume and $25 \mathrm{~kJ} / \mathrm{m}^{2}$ with $27 \%$ with fiber content. Alkali treatment performed on the fibers in $^{[1]}$ resulted in decreased impact resistance of the composites - $11 \mathrm{~kJ} / \mathrm{m}^{2}$ with $20 \%$ fiber volume and $10 \mathrm{~kJ} / \mathrm{m}^{2}$ with $27 \%$ of fibers. Since the fibers used in this work were commercially available ones, with no information regarding any possible pretreatment, it is possible that they were previously processed in a similar manner as reported by Silva et al. ${ }^{[1]}$.

\section{Conclusions}

The objective of this study was to obtain and characterize cold-pressed composites made of polyurethane derived from castor oil and sisal fibers, without the use of coupling agents, through termogravimetric analysis, surface observation and mechanical tests, before and after the incidence of gamma irradiation, with dose of $25 \mathrm{kGy}$. Through thermogravimetric analysis it is possible to conclude that all studied composites showed thermal stability up to $150^{\circ} \mathrm{C}$, even after incidence of gamma radiation, and that none of them had solvents in their composition. SEM cryogenic fractures observation indicated that there was no gap between sisal fibers and polyurethane matrix in any of the materials, even after gamma irradiation. Flexural tests results showed that dispersed fibers composites had lower flexural strength and flexural elastic modulus values. This happened because dispersed fibers extremities act as stress concentration points, diminishing flexural mechanical strength. Non-irradiated woven composites had the highest results in flexural tests, since its interlaced structure provides better load distribution. After radiation incidence, both composites had their mechanical properties decreased. Dispersed fibers composites had better impact resistance when compared to woven composites, which is also explained by the highest amount of inner stresses caused by fibers extremities. Gamma radiation incidence has increased the impact resistance in both materials. Based on these observations it is possible to conclude that these composites are suitable for applications in radio diagnosis and radiotherapy rooms.

\section{Acknowledgements}

The authors gratefully acknowledge CNPq for financial support to this research, and also gratefully acknowledge Cequil for the materials donated to this project. The Multi-User Center for Materials Characterization CMCM of UTFPR-CT is also greatly acknowledged.

\section{References}

1. Silva, R. V., Spinelli, D., Bose Filho, W. W., Claro, S., No., Chierice, G. O., \& Tarpani, J. R. (2006). Fracture toughness of natural fibers/castor oil polyurethane composites. Composites Science and Technology, 66(10), 1328-1335. http://dx.doi. org/10.1016/j.compscitech.2005.10.012.

2. Beckwith, S. W. (2003). Natural fiber reinforcement materials: lower cost technology for composites applications. New York: Compos Fab.

3. Faruk, O., Bledzki, A. K., Fink, H. P., \& Sain, M. (2012). Biocomposites reinforced with natural fibers: 2000-2010. Progress in Polymer Science, 37(11), 1552-1596. http://dx.doi. org/10.1016/j.progpolymsci.2012.04.003.

4. Mohanty, A. K., Misra, M., \& Hinrichsen, G. (2000). Biofibres, biodegradable polymers and biocomposites: an overview. Macromolecular Materials and Engineering, 277(1), 1-24. http:// dx.doi.org/10.1002/(SICI)1439-2054(20000301)276:1<1::AIDMAME1>3.0.CO;2-W.

5. Dittenber, D. B., \& GangaRao, H. V. S. (2012). Critical review of recent publications on use of natural composites in infrastructure. Composites. Part A, Applied Science and Manufacturing, 43(8), 1419-1429. http://dx.doi.org/10.1016/j. compositesa.2011.11.019.

6. Callister, W. D. (2007). Materials science and engineering: an introduction. New York: John Wiley \& Sons.

7. Varghese, S., Kuriakose, B., \& Thomas, S. (1994). Short sisal fibre reinforced natural rubber composites: high-energy radiation, thermal and ozone degradation. Polymer Degradation \& Stability, 44(1), 55-61. http://dx.doi.org/10.1016/01413910(94)90032-9.

8. Azevedo, E. C., Nascimento, E. M., Chierice, G. O., Claro, S., No., \& Lepienski, C. M. (2013). UV and gamma irradiation effects on surface properties of polyurethane derivate from castor oil. Polímeros: Ciência e Tecnologia, 23, 305-311. http:// dx.doi.org/10.4322/polimeros.2013.087.

9. Zini, E., \& Scandola, M. (2011). Green composites: an overview. Polymer Composites, 32(12), 1905-1915. http:// dx.doi.org/10.1002/pc.21224

10. Bledzki, A. K., Reihmane, S., \& Gassan, J. (1996). Properties and modification methods for vegetable fibers for natural fiber composites. Journal of Applied Polymer Science, 59(8), 1329-1336. http://dx.doi.org/10.1002/(SICI)10974628(19960222)59:8<1329::AID-APP17>3.0.CO;2-0.

11. Bledzki, A. K., \& Gassan, J. (1999). Composites reinforced with cellulose based fibres. Progress in Polymer Science, 24(2), 221-274. http://dx.doi.org/10.1016/S0079-6700(98)00018-5.

12. Arbelaiz, A., Fernandez, B., Ramos, J. A., \& Mondragon, I. (2006). Thermal and crystallization studies of short flax fibre reinforced polypropylene matrix composites: effect 
of treatments. Thermochimica Acta, 440(2), 111-121. http:// dx.doi.org/10.1016/j.tca.2005.10.016.

13. Belgacem, M. N., \& Gandini, A. (2005). The surface modification of cellulose fibres for use as reinforcing elements in composite materials. Composite Interfaces, 12(1-2), 41-75. http://dx.doi. org/10.1163/1568554053542188.

14. George, J., Sreekala, M. S., \& Thomas, S. (2001). A review on interface modification and characterization of natural fiber reinforced plastic composites. Polymer Engineering and Science, 41(9), 1471-1485. http://dx.doi.org/10.1002/pen.10846.

15. Kalia, S., Kaith, B. S., \& Kaur, I. (2009). Pretreatments of natural fibers and their application as reinforcing material in polymer composites: a review. Polymer Engineering and Science, 49(7), 1253-1272. http://dx.doi.org/10.1002/pen.21328.

16. Maldas, D., Kokta, B. V., Raj, R. G., \& Daneault, C. (1998). Improvement of the mechanical properties of sawdust wood fibre-polystyrene composites by chemical treatment. Polymer, 29(7), 1255-1265. http://dx.doi.org/10.1016/00323861(88)90053-5.

17. Baiardo, M., Frisoni, G., Scandola, M., \& Licciardello, A. (2002). Surface chemical modification of natural cellulose fibers. Journal of Applied Polymer Science, 83(1), 38-45. http://dx.doi.org/10.1002/app.2229.

18. Baiardo, M., Zini, E., \& Scandola, M. (2004). Flax fibrepolyester composites. Composites. Part A, Applied Science and Manufacturing, 35(6), 703-710. http://dx.doi.org/10.1016/j. compositesa.2004.02.004.

19. Frisoni, G., Baiardo, M., Scandola, M., Lednicka, D., Cnockaert, M. C., Mergaert, J., \& Swings, J. (2001). Natural cellulose fibers: heterogeneous acetylation kinetics and biodegradation behavior. Biomacromolecules, 2(2), 476-482. PMid:11749209. http://dx.doi.org/10.1021/bm0056409.

20. Zini, E., Scandola, M., \& Gatenholm, P. (2003). Heterogeneous acylation of flax fibers. reaction kinetics and surface properties. Biomacromolecules, 4(3), 821-827. PMid:12741804. http:// dx.doi.org/10.1021/bm034040h.

21. Zini, E., Baiardo, M., Armelao, L., \& Scandola, M. (2004). Biodegradable polyesters reinforced with surface-modified vegetable fibers. Macromolecular Bioscience, 4(3), 286-295. PMid:15468219. http://dx.doi.org/10.1002/mabi.200300120.

22. Zini, E., Focarete, M. L., Noda, I., \& Scandola, M. (2007). Bio-composite of bacterial poly(3-hydroxybutyrate-co-3hydroxyhexanoate) reinforced with vegetable fibers. Composites Science and Technology, 67(10), 2085-2094. http://dx.doi. org/10.1016/j.compscitech.2006.11.015.

23. Joseph, K., Thomas, S., \& Pavithran, C. (1996). Effect of chemical treatment on the tensile properties of short sisal fibre-reinforced polyethylene composites. Polymer, 37(23), 5139-5149. http://dx.doi.org/10.1016/0032-3861(96)00144-9.

24. Belgacem, N. M., Bataille, P., \& Sapieha, S. (1994). Effect of corona modification on the mechanical properties of polypropylene/cellulose composites. Journal of Applied
Polymer Science, 53(4), 379-385. http://dx.doi.org/10.1002/ app.1994.070530401.

25. Li, Z. F., \& Netravali, A. N. (1992). Surface modification of UHSPE fibers through allylamine plasma deposition. II. Effect on fiber and fiber/epoxy interface. Journal of Applied Polymer Science, 44(2), 333-346. http://dx.doi.org/10.1002/ app.1992.070440217.

26. Wu, C. S. (2009). Renewable resource-based composites of recycled natural fibers and maleated polylactide bioplastic: characterization and biodegradability. Polymer Degradation \& Stability, 94(7), 1076-1084. http://dx.doi.org/10.1016/j. polymdegradstab.2009.04.002.

27. Karnani, R., Krishnan, M., \& Narayan, R. (1997). Biofiberreinforced polypropylene composites. Polymer Engineering and Science, 37(2), 476-483. http://dx.doi.org/10.1002/pen.11691.

28. Vilar, W. (1999). Química e tecnologia dos poliuretanos. São Paulo: Pronor.

29. Huang, S. J., Edelman, P. G., Scott, G., \& Gilead, D. (1995). Degradable polymers: principles and applications. London: Chapman \& Hall.

30. Azevedo, E. C., Chierice, G. O., Claro, S., No., Soboll, D., Nascimento, E. M., \& Lepienski, C. M. (2010). Gamma radiation effects on mechanical properties and morphology of a polyurethane derivate from castor oil. Radiation Effects and Defects in Solids, 166(3), 208-214. http://dx.doi.org/10. 1080/10420150.2010.525235.

31. Carmona, V., Campos, A., Marconcini, J. M., \& Mattoso, L. H. C. (2014). Kinetics of thermal degradation applied to biocomposites with TPS, PCL and sisal fibers by non-isothermal procedures. Journal of Thermal Analysis and Calorimetry, 115(1), 153-160. http://dx.doi.org/10.1007/s10973-013-3259-0.

32. Suarez, J. C. M., Coutinho, F. M. B., \& Sydenstricker, T. H. (2005). Analysis of the fracture behavior of polypropylene sawdust composites. Polímeros: Ciência e Tecnologia, 15(2), 139-141. http://dx.doi.org/10.1590/S0104-14282005000200015.

33. Borsoi, C., Berwig, K. H., \& Zoppas, L. (2014). Behavior in simulated soil of recycled expanded polystyrene/waste cotton composites. Materials Research, 17(1), 275-283. http://dx.doi. org/10.1590/S1516-14392013005000167.

34. Razera, I. A. T., Silva, C. G., Almeida, É. V. R., \& Frollini, E. (2014). Treatments of jute fibers aiming at improvement of fiberphenolic matrix adhesion macromolecular. Polímeros: Ciência e Tecnologia, 24(4), 417-421. http://dx.doi.org/10.1590/01041428.1738 .

35. Cai, D., Yin, J., \& Liu, R. (2015). Experimental and analytical investigation into the stress performance of composite anchors for CFRP tendons. Composites. Part B, Engineering, 79, 530535. http://dx.doi.org/10.1016/j.compositesb.2015.05.014.

Received: June 03, 2016

Revised: Aug. 22, 2016

Accepted: Dec. 15, 2016 